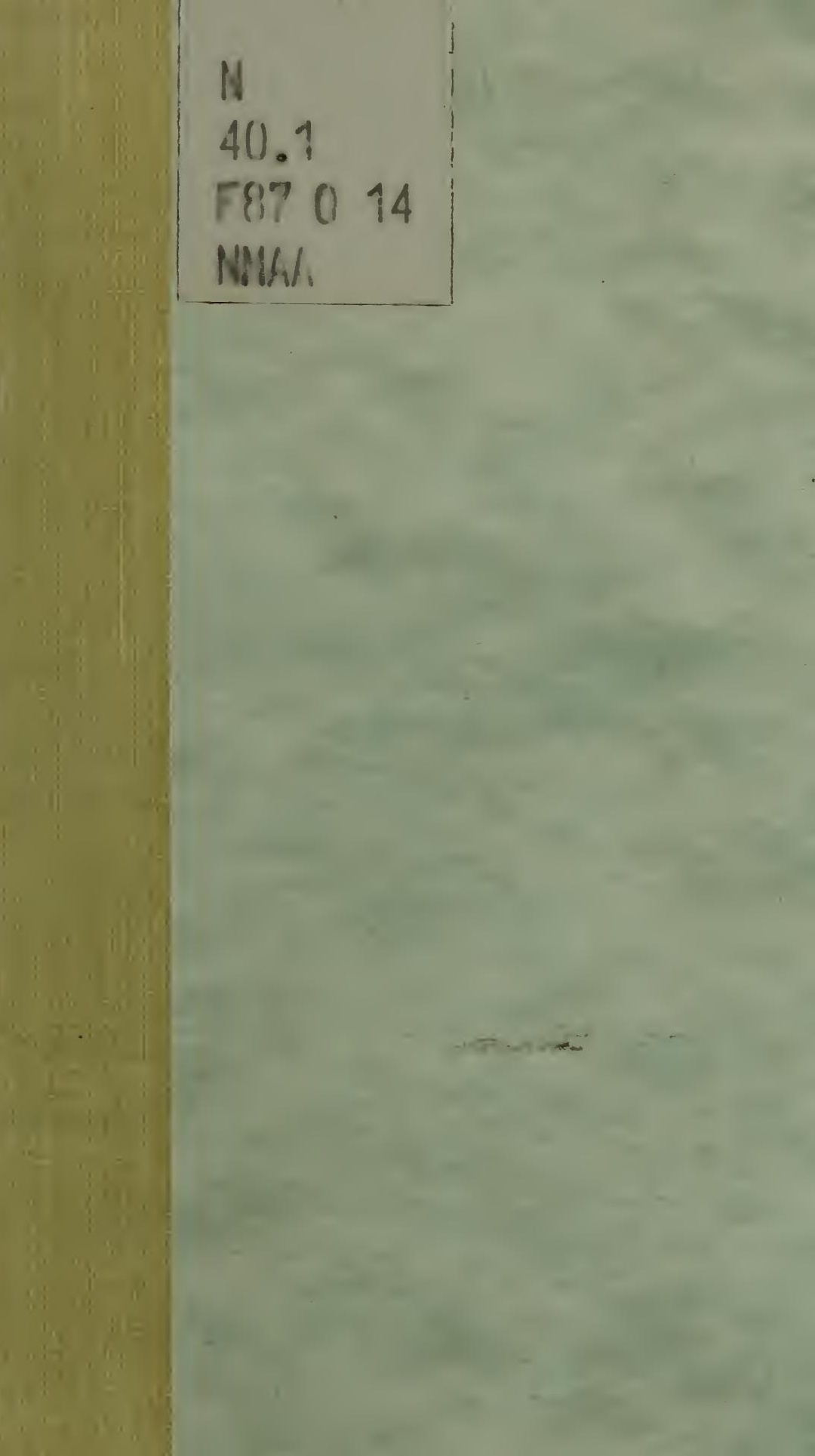





\title{
On Certain Obstacles to the Eidghest Enjoyment of Music
}

\author{
By
}

DNATEL GIUSTRR RHENCH 

(Reprinted by kind permission of The Century Company)

\section{On Certain Obstacles to the Highest Enjoyment of Music}

From a Sculptor, with Practical Suggestions

Dear Mr. Editor:

You flatter me. I am not a musician, and while it was natural enough for me to speak to you of my ideas in regard to the presentation of music, there would seem to be a certain arrogance in my presuming to give them out for the edification of the multitude. However, such as they are, you are welcome to them.

As I told you, some years ago Mrs. spoke at one of the meetings of the Club in criticism of the music that is provided for the opening receptions of some of our art exhibitions. She felt that it was such an offense to the sense of hearing that it interfered with the pleasure of looking at the pictures.

It has seemed to me that the inverse is true of concerts-that the spectacle presented 
to the eye is so ugly and so out of harmony with beautiful music as to be a source of positive pain to many people. What is it that one is forced to see in an orchestral performance, unless he shuts his eyes, as some people do? A multitude of white triangles against a black background, with twice as many white dabs representing cuffs, and with here and there a bald head as a high light in the picture. To raise the eyes to the wall above seldom brings much comfort in our New York music-halls, for they are usually unpleasant in color and shabby from long inattention. Add to this the crowding together of an audience in a badly ventilated place, in a glare of electric light, and you have conditions from which Orpheus would flee in dismay and against which Melpomene would lift her beautiful voice in protest.

Why is it necessary to have so hideous a setting? I am sure something can be done about it, and as a beginning I would take one radical, if negative, step and put the musicians out of sight. Wagner did this with his orchestra in opera, and I believe Mr. Damrosch has talked of doing it in concert, though I think he has never carried out his intention. I know what a storm of protest this would cause from the professional part of 
the music-loving public, and even from some at least of those who are not musicians, because of custom and association. There is no doubt that there is a certain interest in seeing how the sound is produced, but it is a purely technical interest, and has nothing whatever to do with the enjoyment of the sound itself. It is analogous to the interest excited by seeing an artist paint a picture or a glass-blower make a bottle.

Music suggests beauty. The source of music should not be seen. In our imagination it comes from the sea or the sky or the clouds or the throat of a beautiful woman; not the woman who stands in the blaze of the footlights in the latest Paris gown, but the woman whom one's imagination instinctively conjures up when one hears a beautiful voice from an invisible singer.

I could go further in presenting the ideal concert than to hide the musicians. I would subdue the lights to twilight, and I would change the disposition of the seats to a more sympathetic arrangement. Finally, I would provide something in front of the audience that would harmonize with the mood inspired by the particular music rendered. Precisely what this should be I am not prepared to say, but I would be wary of displaying a picture 
or a sculpture, which, however fine, might be distracting, if not positively distasteful, to at least a part of the audience; and I would try to find something elemental,--pertaining to fire or water, earth or sky,-represented perhaps by a flaming altar with ascending smoke or vapor; or a noiseless fountain, illuminated by cool, changing lights; or flowers and trees; or one of the effects of passing clouds that modern photography has made NAC. possible-or the great pearl, the roc's egg that the genius of McKim, more potent than the genius of Aladdin, has hung aloft in the dome of Columbia Library. I am convinced that something should be offered to occupy the eyes, and something that would have in a way a hypnotic effect upon the listener, such as moonlight excites, because it is as true now as in Jessica's time that

. . soft stillness and the night

Become the touches of sweet harmony.

There is another barbarism prevalent which I confess I do not know how to meet, and that is the noise of the applause-the clapping of hands and the general din-that invariably follows and frequently breaks in upon the successful rendering of a composition. It surely is incongruous that the waves of the most beautiful music that mortals can make 
should be rudely broken in this way, and I know there are many people to whom it often comes as a shock, and who would fain be left to continue in the trance into which the music has thrown them; but I also know that to most people applause is a spontaneous outburst not to be suppressed, and, moreover, it comes to the performer as the just recognition of his talent and success. To take it away would be to rob him of the sweetest reward of his work. Still, ordinary humanity has to get along without it. At any rate, in my perfect concert I would prescribe a moment's quiet between the last note of the music and the beginning of the applause. This might at least stop the mouth of the idiot at vocal concerts who shouts "Bravo!" before the song is finished.

I seem to hear my friend the musician, or more likely my closer friend the amateur, say, "But you talk like a Philistine. The real lover of music can enjoy it in any conditions." This is true, but to one of whom it is true, there are ninety-and-nine whose enjoyment is sensuous and in a great measure dependent upon favorable conditions. To these, good music under favorable conditions is preferable to fine music under uncomfortable conditions. I as a sculptor can find en- 
joyment in a statue or a picture though I have to stand in a pelting rain or a biting wind to see it, but I do not expect my non-professional friends to find pleasure in it in such inimical circumstances. Music is not alone, or even chiefly, for the enjoyment of the practitioner, any more than sculpture or painting; nor is its analytical or technical enjoyment the highest form of appreciation of it. I have become gradually aware that many so-called or self-called lovers of music are really

not mov'd with concord of sweet sounds at all, but have come to have a knowledge of what music should be, theoretically and technically, and find their pleasure in it from that source. To these unfortunates, as to a host of people who are not musical by practice or instinct, to be debarred from seeing how the music is made would be a deprivation which they would naturally resent, as also would that other host to whom a change in the presentation of music would be unwelcome as an innovation, the old method being filled with pleasant associations.

I can but believe that the whole plan and arrangement of the present concert-hall should be changed. It was not planned with reference to music at all, but came to be accepted 
as the proper thing from making use of some existing theatre or public hall in which to hold a concert. It is time that the musician and the architect put their heads together and evolved a new plan, one in which the eye and the ear would supplement each other in presenting a perfect harmony of sight and sound.

Faithfully yours,

Daniel C. French. 




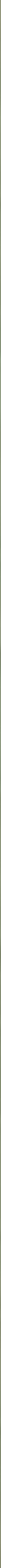


SMITHSONIAN INSTITUTION LIBRARIES

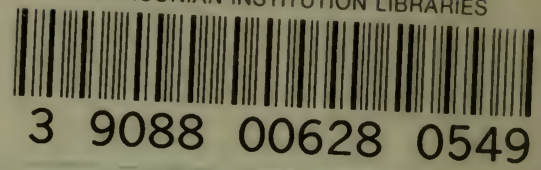

